\title{
Non-destructive analysis of pathological belemnite rostra by micro-CT techniques
}

René Hoffmann, Kevin Stevens, Marie-Claire Picollier, Jörg Mutterlose, and Christian Klug Acta Palaeontologica Polonica 65 (1), 2020: 11-27 doi:https://doi.org/10.4202/app.00689.2019

Previously, palaeopathological features of fossil hardparts were often difficult to interpret because it was impossible to decipher their internal structure without destroying the specimens. We applied high-resolution computedtomo graphy (CT) to document such internal structures. This enabled us to describe a variety of pathologies of Jurassic and Cretaceous belemnite rostra. The examined rostra have been assigned to the taxa ?Acrocoelites sp., Belemnello camax spp., Belemnitella sp., Duvalia emerici, Goniocamax sp., Gonioteuthis spp., Hibolithes jaculoides, Neoclavibelus subclavatus, and Pseudobelus sp. The studied pathologies comprise rostra with two apices, bulges, pearls, broken juvenile rostra, highly porous rostra with abnormal growth increments, blunt-rostra, rostra with callus- like structures, and bent- or knee-shaped rostra. In one rostrum the apex has been turned towards the anterior (alveolus) during ontogeny. Additionally, computed-tomography data were used to document diagenetic alterations of the rostra such as silification, sedimentary infill, pyrite formation. Specimens can also be tested for the presence or absence of internal elements (septa, siphuncle) and surface features. Palaeoecological studies clearly benefit from the application of computed-tomography to gain high resolution images of otherwise invisible internal features of extinct organisms, as demonstrated herein.

Key words: Cephalopoda, Belemnitida, palaeopathology, rostra, micro computed-tomography, diagenesis, Jurassic, Cretaceous, Germany.

René Hoffmann [rene.hoffmann@rub.de], Kevin Stevens [kevin.stevens@ rub.de ], and Jörg Mutterlose [joerg.mutterlose@ rub.de], Institut für Geologie, Mineralogie und Geophysik, Ruhr-Universität Bochum, Universitätsstr. 150, 44801 Bochum, Germany. Marie-Claire Picollier [mc.picollier@wanadoo.fr], La Vitonie, 24160 St. Pantaly d'Excideuil, France. Christian Klug [chklug@pim.uzh.ch], Paläontologisches Institut und Museum, Universität Zürich, Karl-Schmid-Strasse 4, CH-8006 Zürich, Switzerland. 
This is an open-access article distributed under the terms of the Creative Commons

Attribution License (for details please see creativecommons.org), which permits unrestricted use, distribution, and reproduction in any medium, provided the original author and source are credited.

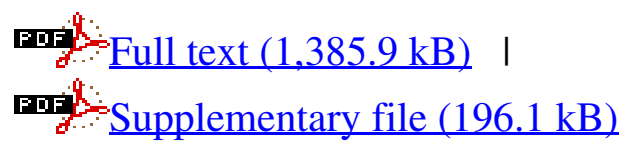

